\title{
Omega-3 Fatty Acid Oil Enhancement of a Protein-Based Recovery Beverage: Sensory Analysis with Athletes
}

\author{
Jessica MacMartin ${ }^{1}$, W. E. Buckley,2, David Cranage ${ }^{3}$, Tim Bream ${ }^{4} \&$ Peter Lawrence Bordi ${ }^{1}$ \\ ${ }^{1}$ Center for Food Innovation, School of Hospitality Management, The Pennsylvania State University, Univesrity \\ Park, Pennsylvania, USA \\ ${ }^{2}$ Department of Kinesiology, The Pennsylvania State University, University Park, Pennsylvania, USA \\ ${ }^{3}$ School of Hospitality Management, The Pennsylvania State University, University Park, Pennsylvania, USA \\ ${ }^{4}$ Athletic Deparment, The Pennsylvania State University, University Park, Pennsylvania, USA \\ Correspondence: Peter Lawrence Bordi, Center for Food Innovation, School of Hospitality Management, The \\ Pennsylvania State University, 124 Mateer Building, University Park, Pennsylvania, 16802, USA. Tel: \\ 814-863-3579. E-mail: plbjr@psu.edu
}

Received: April 7, 2017 Accepted: May 13, $2017 \quad$ Online Published: June 21, 2017

doi:10.5539/jfr.v6n4p83 URL: https://doi.org/10.5539/jfr.v6n4p83

\begin{abstract}
Essential omega-3 fatty acids must be consumed through the diet to meet the body's nutrition requirement. Daily-recommended intake of omega-3 fatty acids for adults is 270 milligrams/day. These fatty acids are commonly consumed through fish, but it is known that the United States population at large is not meeting their recommended daily intake. Supplements containing these important acids should be considered to close the gap between recommendations and actual intake. To create a product with these beneficial acids, sensory analysis was conducted to see if non-trained male and female athlete panelists could notice the difference in several key sensory characteristics (appearance, initial taste, color, sweetness, consistency, chocolate flavor, aftertaste, overall quality and overall liking) in a chocolate protein-based recovery beverage. The sensory-neutral oil was added into the beverage and athletes $(n=95)$ were asked to taste the omega- 3 and original beverage and rank each characteristic on hedonic and just-about-right scales. Color of the drink, aftertaste, overall quality and overall liking were rated significantly higher for the omega-3 added drink. Overall, the addition of the omega-3 fatty acids improved the beverage in several key attributes and can be added into the final formulation of the product.
\end{abstract}

Keywords: athlete, beverage enhancement, omega-3 fatty acid, sensory analysis

\section{Introduction}

The American Heart Association (2017) states that omega-3 polyunsaturated [omega-3] fatty acids have been shown in research to benefit the heart in various ways, such as decreasing the risk of arrhythmias, decreasing triglyceride levels, slowing the rate of growth for atherosclerotic plaque, and lowering blood pressure. Researchers such as Hu et al. (2002), Hu, Cho, Rexrode, Albert, \& Manson (2003), Oomen et al. (2000) and Dewailly, Blanchet, Gingras, Lemieux, \& Holub (2003) have provided well-known observational studies, which have laid the foundation for drawing a connection between omega- 3 fatty acids and heart benefits. In addition, the National Institutes of Health (NIH) reviewed current omega-3 fatty acid research to see if supplementation is effective in the treatment of various health conditions. Omega- 3 fatty acids are currently being studied as a complementary health approach for cardiovascular disease, rheumatoid arthritis, various diseases of the brain and of the eyes, allergies, asthma, Crohn's disease, cystic fibrosis, diabetes, kidney disease, lupus, obesity, and osteoporosis, among many others. Although hard conclusions cannot currently be drawn about omega-3s and their benefits, additional research is still being conducted and funded at a national level (National Center of Complementary and Integrative Health $[\mathrm{NCCIH}], 2015)$.

Scientists began to study the health benefits of long chain omega-3 fatty acids over three decades ago. They found that the Greenland Eskimos had less incidence of heart disease than other ethnic groups despite their high fat diet, which included blubber from marine animals (Bang \& Dyerberg, 1980). Multitudes of recent health and nutrition articles have focused on long chain omega- 3 polyunsaturated fatty acids and their benefits for human health. These include both improved heart health and stronger immune function (Ruxton \& Derbyshire, 2009). 
The current scientific evidence points to improved heart health with the addition of omega-3 into diets through prevention of atrial fibrillation, reduction of hypertension, reduction of fatal ventricular arrhythmias and altered production of prostaglandins. Together, these result in reduced inflammation and improved endothelial and platelet function (Cao et al., 2015).

A growing body of evidence (Fontani et al., 2005; Campoy, Escolano-Margarit, Anjos, Szajewska, \& Uauy, 2012; Hu et al., 2002; Hu et al., 2003) strongly suggests that including or increasing omega-3 intake is important to a healthy diet. Current United States guidelines suggest a combined minimum of 270 milligrams/day for adults of two particular types of omega-3 acids, eicosapentaenoic acid (EPA) and docosahexaenoic acid (DHA) (Institute of Medicine, 2005). One way to ensure that minimum requirements for EPA and DHA are met is through the American Heart Association's recommendation of eating fatty fish at least two times (two servings of 3.5 ounces cooked) per week. Although it is preferred to consume omega-3 fatty acids through food, supplementation may be necessary for those with coronary heart disease who need more than they can reasonably consume through diet alone, or for those who need to be careful of mercury or other environmental contaminants intake ("Fish and Omega-3 Fatty Acids,” 2015).

Of special interest are EPA and DHA, two long chain omega-3 polyunsaturated fatty acids (LC3PUFA). As a country, we chronically under-consume these essential acids; what we do get is provided through aquatic life and fish (Forchielli \& Walker, 2011). Rich sources of LC3PUFA include salmon, trout, herring, mackerel, lake trout, and sardines ("Fish and Omega-3 Fatty Acids," 2015). Other common sources of omega-3 fatty acids other than fish and marine life include some vegetable oils, walnuts, chia and hemp seeds, and soy foods, such as edamame or soybeans (Denny, 2015). There is moderate evidence that the addition of fatty fish to one's regular diet is beneficial, but the benefits of omega-3 supplementation are still unclear (NCCIH, 2016). Although the demand for marine omega- 3 fatty acids have been increasing steadily, the production of these oils is stable and not expected to increase due to sustainability concerns (Tur, Bibiloni, Sureda, \& Pons, 2012).

National Health and Nutrition Examination Survey (NHANES) reports the average consumption of omega-3 fatty acids in the population of 19 years and older in the United States. NHANES found that the average intake of fish high in omega- 3 fatty acids was $0.15 \pm 0.03$ ounces per day (Papanikolaou, Brooks, Reider, \& Fulgoni, 2014). This is well below the recommendation from the American Heart Association (2016) of approximately one ounce on average per day. Considering that heart disease is the leading cause of death in the United States, accounting for one in four deaths or 600,000 deaths per year, it affects individuals across the country, regardless of their gender or ethnicity ("Heart Disease Facts," 2015). It was estimated that in 2011, cardiovascular disease cost $\$ 320.1$ billion dollars for treatment, medications, and lost productivity (Mozaffarian et al., 2015).

Omega-3 fatty acid benefits have been studied in athletes. Atashak et al. (2013) studied their positive effects that daily omega-3 supplementation had on blood levels of oxidative stress, muscle damage, and inflammation markers in athletes. Hasadsri et al. (2013) reviewed several studies on omega-3 fatty acids as a potential treatment for traumatic brain injuries (e.g. concussions). Additional research needs to be completed for evidence to be conclusive.

There is suggestive but not conclusive evidence linking omega-3 fatty acid supplementation with various benefits (Balk et al., 2016). As the American Cancer Society (2015) points out, supplements are not required to go through rigorous testing like pharmaceuticals and thus may pose a risk to health. This may be a concern, as a few studies have potentially found correlations between omega-3 fatty acid blood levels to prostate cancer (Brett, 2013).

This study aims to discover if 50 milligrams of essential omega- 3 fatty acid oil can be added into a serving of a protein-based recovery drink and remain sensory-neutral from a consumer's standpoint. Sensory analysis for this purpose can be conducted as a product comparison test, as it is an effective way to gauge consumer liking and what factors may be driving that liking (Sensory Analysis Center, 2015). Conducting sensory analysis is important to ensure that the product is still acceptable after the reformulation, as it is known that liking a food item has a strong positive correlation with intake (Byrnes \& Hayes, 2013). If the sensory properties were degraded, the formulation would need to be reconsidered, as the negative attributes may sway individuals to not consume the beverage, regardless of health benefits. In addition, as Lawless and Heymann (2010) point out, studying the sensory characteristics and attributes of a product by utilizing consumer's opinion and their point of view is useful information to the developers of the product. In this case, a chocolate protein-based recovery beverage enhanced with omega-3 fatty acids will be compared against the original chocolate beverage without the fatty acids. 


\section{Methodology and Materials}

Data collection was conducted on iPads in the athletic training rooms of male and female athletes at a large university in the northeastern United States. Athletes were given both the original recovery drink and the omega-3 enhanced recovery drink in 5-ounce plastic cups at the same time, individually labeled with three-digit blinding codes. Participants were asked to taste and rank each beverage for several sensory characteristics and select their overall preference.

\subsection{Beverage Development}

The original beverage has been formulated with a research-based protein formula intended for athletic recovery and was available for athletes and all consumers at the university. The current protein formula has been developed to ease soreness, accelerate muscle growth, and prevent injuries (Reidy et al., 2014). The beverage was produced on the university campus and was tested extensively for quality and consumer preferences. The omega-3 enhanced recovery beverage was also formulated at the university, with the addition of omega-3 fatty acids. As mentioned previously, 50 milligrams of omega- 3 oil have been added into each serving. Both of the beverages nutritional information has been detailed in Table 1 and Table 2.

The omega- 3 enhanced beverage is nearly identical to the original beverage when considering the nutrition and the composition. All ingredients were kept constant, with the exception of the milk solids. Milk solids are composed of fat (International Dairy Foods Association, 2017), and thus were pulled out to offset the addition of fat from the omega-3 oil. The goal of this reformulation was to keep the nutritional components nearly identical while replacing the fat from the milk solids with a fat that has health benefits.

Table 1. Nutritional Information for Original Recovery Beverage

\begin{tabular}{ll}
\hline \multicolumn{1}{c}{ Original Beverage, $\mathbf{1 2 ~ o z}$} \\
\hline Calories & 338 \\
Calories from Fat & 68 \\
Total Fat & $8 \mathrm{~g}$ \\
Saturated Fat & $5 \mathrm{~g}$ \\
Trans Fat & $0 \mathrm{~g}$ \\
Cholesterol & $26 \mathrm{mg}$ \\
Sodium & $473 \mathrm{mg}$ \\
Total Carbohydrate & $41 \mathrm{~g}$ \\
Dietary Fiber & $0 \mathrm{~g}$ \\
Sugars & $39 \mathrm{~g}$ \\
Protein & $26 \mathrm{~g}$ \\
\hline
\end{tabular}

Table 2. Nutritional Information for Omega-3 Enhanced Recovery Beverage

\begin{tabular}{ll}
\hline \multicolumn{2}{c}{ Omega-3 Enhanced Beverage, 12 oz } \\
\hline Calories & 310 \\
Calories from Fat & 45 \\
Total Fat & $5 \mathrm{~g}$ \\
Saturated Fat & $3 \mathrm{~g}$ \\
Trans Fat & $0 \mathrm{~g}$ \\
Cholesterol & $25 \mathrm{mg}$ \\
Sodium & $340 \mathrm{mg}$ \\
Total Carbohydrate & $40 \mathrm{~g}$ \\
Dietary Fiber & $2 \mathrm{~g}$ \\
Sugars & $37 \mathrm{~g}$ \\
Protein & $23 \mathrm{~g}$ \\
\hline
\end{tabular}

\subsection{Testing Procedure}

Individuals were pre-screened for potential allergies and intolerances and informed of potential risks before participation. Samples of each drink were served in 5-ounce clear plastic cups for the taste test. Compusense Cloud software (Compusense Cloud, Compusense Inc., Canada) was utilized to collect data on the tablets and run initial statistical analysis. The Institutional Review Board (IRB) assigned the following submission approval number: IRB \#00004465. 


\subsection{Participants}

A total of 95 male and female athlete participants were recruited on a volunteer basis from various athletic teams across the university. Age and gender breakdowns are offered in Table 3 and 4. Most of the participants work out 6-7 times per week (78 participants; 82.11\%), with the minimum number of workouts for a participant being 3 times per week (1 participant, 1.05\%). Sport involvement for the participants included football, lacrosse, field hockey, tennis, rugby, soccer and swimming, and is offered in a breakdown by gender in Table 4. A majority of the recruited participants were male football players because this demographic most commonly consumes the recovery beverage at the university. Athletes were separated during testing to ensure their peers did not influence their opinions.

Table 3. Participants' Age Distribution

\begin{tabular}{ccc}
\hline Age Group & Frequency & Percent \\
\hline $18-19$ & 36 & $37.89 \%$ \\
$20-21$ & 48 & $50.53 \%$ \\
$22-23$ & 10 & $10.53 \%$ \\
$24-25$ & 1 & $1.05 \%$ \\
\hline Total & $\mathbf{9 5}$ & $\mathbf{1 0 0 . 0 0 \%}$ \\
\hline
\end{tabular}

Table 4. Participants' Sport Involvement

\begin{tabular}{ccc}
\hline Sport & Male & Female \\
\hline Football & 45 & 0 \\
Lacrosse & 17 & 10 \\
Field Hockey & 0 & 12 \\
Tennis & 0 & 6 \\
Rugby & 0 & 3 \\
Soccer & 0 & 1 \\
Swimming & 0 & 1 \\
\hline Total & $\mathbf{6 2}$ & $\mathbf{3 3}$ \\
(N=95) & $\mathbf{( 6 5 . 2 6 \% )}$ & $\mathbf{( 3 4 . 7 4 \% )}$ \\
\hline
\end{tabular}

\subsection{Sensory Evaluation}

Participants were requested to rate the following sensory characteristics on a 9-point hedonic scale: appearance, initial taste, aftertaste, overall quality and overall liking. Color of the drink, sweetness, consistency and chocolate flavor were rated on a 5-point JAR (just about right) scale to determine the appropriateness of the level of each specific attribute. In addition, participants were asked to indicate their preference between the two samples

\section{Results and Discussion}

To compare sensory differences between the plain recovery protein beverage and the omega- 3 supplemented beverage, paired t-tests were employed. The means, standard deviations, calculated t-value and resulting $\mathrm{p}$-value are shown in Table 5 for all participants, while male and female data are broken down in Table 6.

Table 5. Mean Comparison Between Original and Omega-3 Added

\begin{tabular}{lllllll}
\hline & \multicolumn{2}{c}{ Original } & \multicolumn{2}{c}{ Omega-3 Added } & \multicolumn{2}{c}{ Differences } \\
\cline { 2 - 7 } & Mean & SD & Mean & SD & T & p-value \\
\hline Appearance $^{\mathrm{a}}$ & 7.24 & 1.12 & 6.84 & 1.19 & 3.38 & $\mathbf{0 . 0 0}$ \\
Initial Taste $^{\mathrm{a}}$ & 7.02 & 1.44 & 7.07 & 1.31 & -0.27 & 0.79 \\
Color of Drink $^{\mathrm{b}}$ & 2.87 & 0.33 & 2.99 & 0.31 & -2.46 & $\mathbf{0 . 0 2}$ \\
Sweetness $^{\mathrm{c}}$ & 2.94 & 0.60 & 2.81 & 0.49 & 1.65 & 0.10 \\
Consistency $^{\mathrm{d}}$ & 3.01 & 0.56 & 3.05 & 0.51 & -0.58 & 0.57 \\
Chocolate Flavor $^{\mathrm{e}}$ & 2.68 & 0.64 & 2.78 & 0.53 & -1.22 & 0.23 \\
Aftertaste $^{\mathrm{a}}$ & 5.65 & 1.68 & 6.61 & 1.63 & -5.13 & $\mathbf{0 . 0 0}$ \\
Overall Quality $^{\text {a }}$ & 6.85 & 1.25 & 7.18 & 1.18 & -2.27 & $\mathbf{0 . 0 3}$ \\
Overall Liking $^{\mathrm{a}}$ & 6.87 & 1.42 & 7.29 & 1.23 & -2.40 & $\mathbf{0 . 0 2}$ \\
\hline
\end{tabular}

${ }^{a}$ Nine-point hedonic scale, where $1=$ dislike extremely, $2=$ dislike very much, $3=$ dislike moderately, $4=$ dislike slightly, $5=$ neither like nor dislike, $6=$ like slightly, $7=$ like moderately, $8=$ like very much, $9=$ like extremely 


\footnotetext{
${ }^{\mathrm{b}}$ Five-point just about right (JAR) scale: $1=$ too light, $2=$ slightly too light, $3=$ just about right, $4=$ slightly too dark, $5=$ too dark

${ }^{\mathrm{c}}$ Five-point JAR scale: $1=$ not sweet, $2=$ slightly not sweet, $3=$ just about right, $4=$ slightly too sweet, $5=$ too sweet

${ }^{\mathrm{d}}$ Five-point JAR scale: $1=$ too thin, $2=$ slightly too thin, $3=$ just about right, $4=$ slightly too thick, $5=$ too thick

${ }^{\mathrm{e}}$ Five-point JAR scale: $1=$ too weak, 2 = slightly too weak, $3=$ just about right, $4=$ =slightly too strong, $5=$ =too strong $* \mathrm{p}<0.05, * * \mathrm{p}<0.01$
}

Table 6. Mean Comparison Between Original and Omega-3 Added for Males and Females

\begin{tabular}{|c|c|c|c|c|c|c|c|c|c|c|c|c|}
\hline & \multicolumn{6}{|c|}{ Males } & \multicolumn{6}{|c|}{ Females } \\
\hline & \multicolumn{2}{|c|}{ Original } & \multicolumn{2}{|c|}{ Omega-3 } & \multicolumn{2}{|c|}{ Differences } & \multicolumn{2}{|c|}{ Original } & \multicolumn{2}{|c|}{ Omega-3 } & \multicolumn{2}{|c|}{ Differences } \\
\hline & Mean & SD & Mean & SD & $\mathrm{T}$ & p-value & Mean & SD & Mean & $\mathrm{SD}$ & $\mathrm{T}$ & p-value \\
\hline Appearance $^{\mathrm{a}}$ & 7.16 & 1.10 & 6.84 & 1.18 & 2.22 & $0.03 *$ & 7.39 & 1.14 & 6.85 & 1.23 & 2.67 & $0.01 * *$ \\
\hline Initial Taste $^{\mathrm{a}}$ & 7.29 & 1.11 & 6.98 & 1.41 & 1.42 & 0.16 & 6.52 & 1.84 & 7.24 & 1.09 & -1.94 & 0.06 \\
\hline Color of Drink ${ }^{\mathrm{b}}$ & 2.87 & 0.34 & 2.98 & 0.38 & -1.72 & 0.09 & 2.88 & 0.33 & 3.00 & 0.00 & -2.10 & $0.04 *$ \\
\hline Sweetness ${ }^{c}$ & 2.97 & 0.60 & 2.79 & 0.49 & 2.02 & $0.05^{*}$ & 2.88 & 0.70 & 2.85 & 0.36 & 0.21 & 0.84 \\
\hline Consistency $^{\mathrm{d}}$ & 2.94 & 0.54 & 3.03 & 0.51 & -1.14 & 0.26 & 3.15 & 0.57 & 3.09 & 0.52 & 0.44 & 0.66 \\
\hline Chocolate Flavor $^{e}$ & 2.74 & 0.60 & 2.82 & 0.56 & -0.84 & 0.40 & 2.58 & 0.71 & 2.70 & 0.47 & -0.89 & 0.38 \\
\hline Aftertaste $^{\mathrm{a}}$ & 5.68 & 1.68 & 6.42 & 1.74 & -3.01 & $0.00 * *$ & 5.61 & 1.71 & 6.67 & 1.33 & -5.16 & $0.00 * *$ \\
\hline Overall Quality $^{\mathrm{a}}$ & 7.06 & 1.07 & 7.08 & 1.15 & -0.11 & 0.92 & 6.45 & 1.46 & 7.36 & 1.22 & -3.29 & $0.00 * *$ \\
\hline Overall Liking ${ }^{\mathrm{a}}$ & 7.05 & 1.18 & 7.18 & 1.18 & -0.69 & 0.49 & 6.55 & 1.75 & 7.52 & 1.30 & -2.80 & $0.01 * *$ \\
\hline
\end{tabular}

a, b, c, d, **,** Scales above are the same used in Table 5

When comparing the original protein beverage to the omega-3 protein beverage amongst all participants, appearance, color of the drink, aftertaste, overall quality and overall liking were rated significantly different. Appearance and aftertaste were the only two characteristics that consistently had significant findings for both genders. It is possible that the difference in appearance was found due to the omega- 3 enhanced beverage appearing to be more "glossy" due to the addition of the oil. Taste, consistency, and chocolate flavor were unaffected by the addition of omega-3's, thus characteristics key to athlete/consumer acceptance were comparable between beverages. Indeed, means for the omega-3 drink were higher for these attributes: color, aftertaste, quality and liking.

The gender breakdown in Table 6 shows that females rated the overall quality and the overall liking of the omega-3 enhanced beverage higher over the original beverage, while males did not. While is documented that men and women differ in their taste perceptions (Leshem, Haliwa, Hochman, \& Manasherov, 2008), it is important to consider the sample size and proportion of women in this study $\left(\mathrm{n}_{\text {Women }}=33, \mathrm{n}_{\text {Total participants }}=95\right)$. It is possible that if more females participated in this study, the same results would not occur. This warrants additional investigation on the differences in taste perception between males and females, and how those perceptions influence their final decisions on how to rate key sensory attributes.

At the end of the test, individuals were asked which of the two drinks they preferred. Table 7 details the individual response rates within the group and between males and females. The analysis was carried out using the total number of responses, with both genders grouped together. As suggested by Lawless \& Heymann (2010), because the "no preference" option has below $20 \%$ of responses (actual percentage 16.84\%), the no-preference option is eliminated for the purposes of analysis. For the, remaining responses $(n=79)$, the minimum value required for a significant difference with an alpha criterion is 49 (Lawless \& Heymann, 2010). Among those expressing a preference, there was a significant preference for the omega-3 beverage. When looking at whether there was a statistically significant difference amongst the male responses, 34 individuals would have had to indicate a preference for one of the beverages, but only 22 males preferred the original beverage and 29 preferred the omega- 3 beverage. However, there was a significant difference amongst the female responses. This required a minimum of 20 (Lawless \& Heymann, 2010) females to express a preference for one drink. Because the omega-3 added drink had 21 females responding that they favored it, there was a significant difference in preference for females. 
Table 7. Preference Test

\begin{tabular}{cccc}
\hline Preference & Male Responses & Female Responses & Total Number of Responses \\
\hline Original & $22(35.48 \%)$ & $7(21.21 \%)$ & $29(30.53 \%)$ \\
\hline Omega-3 Added & $29(46.77 \%)$ & $21(63.64 \%)$ & $50(52.63 \%)$ \\
\hline I prefer both equally & $11(17.74 \%)$ & $5(15.15 \%)$ & $16(16.84 \%)$ \\
\hline
\end{tabular}

\section{Conclusion}

Before finalizing any new product reformulation changes, it is important to verify that the major sensory attributes are not negatively affected by the addition or subtraction of ingredients. The present study showed that it is possible to enhance a milk-based protein recovery beverage with omega-3 fatty acids and not have the sensory results degraded. In fact, several attributes important to consumers when choosing a beverage were improved, including the color of the drink, aftertaste, overall quality and overall liking. This confirms that incorporating omega-3 fatty acid oils into the beverage is advantageous, due to the presumed health benefits gained without hurting (indeed improving) the quality of the drink. It is key to realize that liking of a food has a strong, positive correlation with intake (Byrnes \& Hayes, 2013), indicating that the significant difference found between overall liking in this experiment is very important, as it favors the omega- 3 containing beverage. Although not all of the attributes came out as favoring the omega- 3 beverage, overall liking is perhaps the most important.

Because of the need to incorporate more essential fatty acids into American's diets, researchers and product developers should continue to test the addition of omega-3 acids into a larger range of beverage and food products.

\section{Funding Sources/Conflict of Interest}

This research did not receive any specific grant from funding agencies in the public, commercial or not-for-profit sectors.

\section{References}

American Cancer Society. (2015). Risks and side effects of dietary supplements. Retrieved from https://www.cancer.org/treatment/treatments-and-side-effects/complementary-and-alternative-medicine/diet ary-supplements/risks-and-side-effects.html

American Heart Association. (2016). Fish and omega-3 fatty acids. Retrieved from http://www.heart.org/HEARTORG/HealthyLiving/HealthyEating/HealthyDietGoals/Fish-and-Omega-3-Fatt y-Acids_UCM_303248_Article.jsp\#.WK-JmLYrI0Q

American Heart Association. (2017). Heart and stroke encyclopedia: Omega-3 fatty acids. Retrieved from http://www.heart.org/HEARTORG/Encyclopedia/Heart-Encyclopedia_UCM_445084_Encyclopedia.jsp?lev elSelected $=15 \&$ title $=$ omega $\% 203 \% 20$ fatty $\% 20$ acids

Atashak, S., Sharafi, H., Azarbayjani, M. A., Stannard, S. R., Goli, M. A., \& Haghighi, M. M. (2013). Effect of omega 3 supplementation on the blood levels of oxidative stress, muscle damage and inflammation markers after acute resistance exercise in young athletes. Kinesiology, 45(1), 22-29. Retrieved from https://www.ebscohost.com/academic/sportdiscuss-with-full-text/

Balk, E. M., Adam, G. P., Langberg, V., Halladay, C, Chung, M., Lin, L., \& Trikalinos, T. A. (2016). Omega-3 Fatty Acids and Cardiovascular Disease: An Updated Systematic Review. Evidence Report/Technology Assessment No. 223. (Prepared by the Brown Evidence-based Practice Center under Contract No. 290-2012-00012-I.) AHRQ Publication No. 16-E002-EF. Rockville, MD: Agency for Healthcare Research and Quality. Retrieved from www.effectivehealthcare.ahrq.gov/reports/final.cfm

Bang, H. O., \& Dyerberg, J. E. (1980). Lipid metabolism and ischemic heart disease in Greenland Eskimos. In H. H. Draper (Ed.), Advances in Nutritional Research, 1-22. https://doi.org/10.1007/978-1-4757-4448-4_1

Brett, A. S. (2013). Higher [omega]-3 fatty acid levels are associated with risk for prostate cancer. NEJM Journal Watch General Medicine, 105(1132). https://doi.org/10.1056/nejm-jw.NA31812

Byrnes, N. K., \& Hayes, J. E. (2013). Personality factors predict spicy food liking and intake. Food Quality Preference, 28(1), 213-221. https://doi.org/10.1016/j.foodqual.2012.09.008

Campoy, C., Escolano-Margarit, M. V., Anjos, T., Szajewska, H., \& Uauy, R. (2012). Omega 3-fatty acids on child growth, visual acuity and neurodevelopment. The British Journal of Nutrition, 107, S85-S106. 
https://doi.org/10.1017/S0007114512001493

Cao, Y., Lu, L., Liang, J., Liu, M., Li, X., Sun, R., ... Zhang, P. (2015). Omega-3 fatty acids and primary and secondary prevention of cardiovascular disease. Cell Biochemistry and Biophysics, 72(1), 77-81. https://doi.org/10.1007/s12013-014-0407-5

Compusense Cloud [Computer software]. 2017. Retrieved from https://www.compusense.com

Denny, S. (2015, May 19). What are Omega-3 fatty acids? Retrieved on August 14, 2016 from http://www.eatright.org/resource/food/vitamins-and-supplements/types-of-vitamins-and-nutrients/what-areomega-3-fatty-acids

Dewailly, E., Blanchet, C., Gingras, S., Lemieux, S., \& Holub, B. J. (2003). Fish consumption and blood lipids in three ethnic groups of Québec (Canada). Lipids, 38(4), 359-365. https://doi.org/10.1007/s11745-003-1070-4

Fish and Omega-3 Fatty Acids. (2015). Retrieved from http://www.heart.org/HEARTORG/HealthyLiving/HealthyEating/HealthyDietGoals/Fish

Fontani, G., Corradeschi, F., Felici, A., Alfatti, F., Migliorini, S., \& Lodi, L. (2005). Cognitive and physiological effects of Omega - 3 polyunsaturated fatty acid supplementation in healthy subjects. European Journal of Clinical Investigation, 35(11), 691-699. https://doi.org/10.1111/j.1365-2362.2005.01570.x

Forchielli, M. L., \& Walker, W. A. (2011). [Omega]-3 fatty acids: Impact on cognitive development and inflammation. Nutrition Today, 46(5), 224-234. https://doi.org/10.1097/NT.0b013e3182303fc4

Hasadsri, L., Wang, B. H., Lee, J. V., Erdman, J. W., Llano, D. A., Barbey, A. K., \& Wang, H. (2013). Omega-3 fatty acids as a putative treatment for traumatic brain injury. Journal of Neurotrauma, 30(11), 897-906. https://doi.org/10.1089/neu.2012.2672

Heart Disease Facts. (2015, August 10). Retrieved on August 17, 2016 from http://www.cdc.gov/heartdisease.facts

Hu, F. B., Bronner, L., Willett, W. C., Stampfer, M. J., Rexrode, K. M., Albert, C. M., ... Manson, J. E. (2002). Fish and omega-3 fatty acid intake and risk of coronary heart disease in women. Journal of the American Medical Association, 287(14), 1815-1821. https://doi.org/10.1001/jama.287.14.1815

Hu, F. B., Cho, E., Rexrode, K. M., Albert, C. M., \& Manson, J. E. (2003). Fish and long-chain omega-3 fatty acid intake and risk of coronary heart disease and total mortality in diabetic women. Circulation, 107(14), 1852-1857. https://doi.org/10.1161/01.CIR.0000062644.42133.5F

Institute of Medicine. (2005). Dietary Reference Intakes for Energy, Carbohydrate, Fiber, Fat, Fatty Acids, Cholesterol, Protein and Amino Acids. Food and Nutrition Board. The National Academies Press: Washington, DC. https://doi.org/10.17226/10490

International Dairy Foods Association. (2017). Definitions. Retrieved from http://www.idfa.org/news-views/media-kits/milk/definition

Lawless, H. T., \& Heymann, H. (2010). Sensory evaluation of food: Principles and practices (2nd ed.). New York, NY: Springer.Leshem, M., Haliwa, M., Hochman, A., Manasherov, M., \& Yaccobi, A. (2008). Gender differences in basic taste perception. Appetite, 51(2), 381. https://doi.org/10.1016/j.appet.2008.04.146

Mozaffarian, D., Benjamin, E. J., Go, A. S., Arnett, D. K., Blaha, M. J., Cushman, M., ... Turner, M. B. (2015). Heart disease and stroke statistics-2015 update: A report from the American Heart Association. Circulation, 131(4), e29-e322. https://doi.org/10.1161/CIR.0000000000000152

National Center for Complementary and Integrative Health. (2015). Omega-3 supplements: In depth. (NCCIH Publication No. D482). Washington, DC: U.S. Government Printing Office.

Oomen, C. M., Feskens, E. J., Räsänen, L., Fidanza, F., Nissinen, A. M., Menotti, A., ... Kromhout, D. (2000). Fish consumption and coronary heart disease mortality in Finland, Italy, and the Netherlands. American Journal of Epidemiology, 151(10), 999-1006. https://doi.org/10.1093/oxfordjournals.aje.a010144

Papanikolaou, Y., Brooks, J., Reider, C., \& Fulgoni, Victor, L. F. (2014). U.S. adults are not meeting recommended levels for fish and omega-3 fatty acid intake: Results of an analysis using observational data fromNHANES 2003-2008. Nutrition Journal, 13(31). https://doi.org/10.1186/1475-2891-13-31

Reidy, P. T., Walker, D. K., Dickinson, J. M., Gundermann, D. M., Drummond, M. J., Timmerman, K. L., ... Rasmussen, B. B. (2014). Soy-dairy protein blend and whey protein ingestion after resistance exercise 
increase amino acid transport and transporter expression in human skeletal muscle. Journal of Applied Physiology, 116(11). https://doi.org/10.1152/japplphysiol.01093.2013

Ruxton, C. H. S. \& Derbyshire, E. (2009). Latest evidence on omega-3 fatty acids and health. Nutrition and Food Science, 39(4), 423-438. https://doi.org/10.1108/0034665910976293

Sensory Analysis Center. (2015). Consumer Product Comparison Tests. Retrieved from http://www.sensoryanalysis.com/services/consumer-evaluation/product-comparison-tests.html

Tur, J. A., Bibiloni, M. M., Sureda, A., \& Pons, A. (2012). Dietary sources of omega 3 fatty acids: Public health risks and benefits. The British Journal of Nutrition, 107, S23-S52. https://doi.org/10.1017/S0007114512001456

\section{Copyrights}

Copyright for this article is retained by the author(s), with first publication rights granted to the journal.

This is an open-access article distributed under the terms and conditions of the Creative Commons Attribution license (http://creativecommons.org/licenses/by/4.0/). 